\title{
Iot Based Water Quality Testing System In Aquaculture
}

\author{
M. Rohith Ananth Ratnam, B. Priyanka, J. I. Chakravathy, K. Venkata Phani Raja
}

\begin{abstract}
An Aquaculture delivers more protein to address worldwide yearning, bolster the economy, make more occupations and furthermore uses our assets all the more productively, amplifying the utilization of our territory and water. About portion of the world's fish is an aftereffect of aquaculture. The water quality in aquaculture is checked utilizing sensors to guarantee development and survival of oceanic life. The detected information is exchanged to web utilizing Raspberry pi module. The framework naturally evacuates the waste water and fills the crisp water utilizing engine siphon.
\end{abstract}

\section{Keywords: Raspberry Pi}

\section{INTRODUCTION}

The term aquaculture for the most part alludes to reproducing, raising and collecting of plants and creatures in a wide range of sea-going condition, for example, lakes, lakes, waterways and seas.

Aquaculture additionally incorporates raising harvest estimate fish from incubation center fish and shellfish, which can be brought up in tanks, enclosures, lakes, or raceways. Some aquaculture rehearses are utilized to upgrade the wild load of fish by understanding the incubation center fish into the wild to improve or reconstruct wild fish populaces.

Water is one of the most fundamental standard asset that has been talented to the mankind. In any case, the quick improvement of the general populace and distinctive human exercises speeded up the sullying and separated the water assets. For above water quality checking is basic to see any adjustments in water quality parameters every so often to ensure its flourishing consistently [1].

A thought of 'Submerged Wireless Sensor Network' (UWSN) is the fundamental structure square of a water quality watching utilizing remote sensor sort out (WSN) advancement obliged by sunlight based board. To screen

Revised Manuscript Received on August 14, 2019.

Mr. M. Rohith Ananth Ratnam, Assistant Professor, ECE Department, Malla Reddy Institute of Technology and Science, Hyderabad, Telangana, India (email ID: rohith.ananthratnam@gmail.com)

Ms. B. Priyanka, M.Tech Scholar, ECE Department, Malla Reddy Institute of Technology and Science, Hyderabad, Telangana, India (email ID: priyankabotla7@gmail.com)

Mr. J. I. Chakravathy, Assistant Professor, ECE Department, Malla Reddy Institute of Technology and Science, Hyderabad, Telangana, India (email ID: j.i.chakravarthy@gmail.com)

Mr. K. Venkata Phani Raja Assistant Professor, ECE Department, Malla Reddy Institute of Technology and Science, Hyderabad, Telangana, India (email ID: venkataphaniraja@gmail.com) water quality over various locale as a consistent application, a hair-raising structure building contained by dissipated sensor focuses and a base station is proposed [4].

The plausibility of the Internet of Things (IoT) started in the Auto-ID Center at the Massachusetts Institute of Technology in 1999. The Auto-ID Center imagines a world wherein every single electronic gadget are arranged and each article, paying little regard to whether physical or electronic, is electronically named with data fitting to that object. The fundamental motivation behind this idea is the accomplishment of unavoidable connection between the Internet and things around us; that is, stretching out the present Internet to merge interconnected physical articles and gadgets (i.e., Things) [3].

\section{RASPBERRY PI}

Figure 1 displays The Raspberry $\mathrm{Pi}$ is a charge card surveyed single-board PC made in the UK by the Raspberry Pi Foundation with the yearning for moving the teaching of central programming working in schools. Rather than a microcontroller board, the Raspberry Pi is a full scale PC at an incredibly poor expense. The Raspberry Pi circuit board, with parts and affiliations stuck on it is showed up in Figure.

It is considered as heart of this planning. Raspberry pi is an irrelevant effort, little PC board with Linux as working structure. It has two or three focal centers when stood apart from other downsized scale controllers, for example, inbuilt Wi-Fi module. The Program for get-together the sensor information is written in python language and sends that information to the cloud database [2].

The Raspberry Pi has a cheap ARM processor based single board PC running the GNU/LINUX working framework. The core of a Raspberry $\mathrm{Pi}$ is indistinguishable processor from in iPhone $3 \mathrm{G}$ and Kindle 2, so it claims plenteous capacities similar to those ground-breaking little gadgets. It is fueled by BCM2835 System on chip from Broadcom that contains an ARM processor running at $700 \mathrm{MHz}$

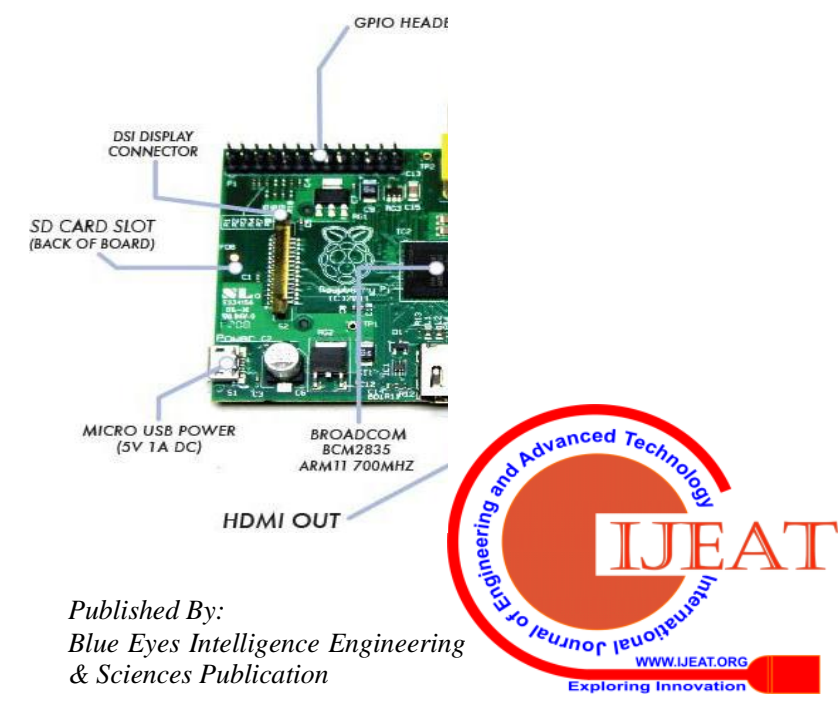




\section{Figure 1 Raspberry Pi Module.}

\section{PH SENSOR (SEN 0161)}

Figure 2 shows the $\mathrm{pH}$ sensor module, $\mathrm{pH}$ esteem effortlessly. Comes in minimized plastic box with froths for better portable stockpiling. Consideration: In request to guarantee the exactness of the $\mathrm{pH}$ test, you have to utilize the standard answer for adjust it frequently. For the most part, the period is about a large portion of a year. In the event that you measure the messy watery arrangement, you have to expand the recurrence of adjustment.

Please utilize an outside exchanging power supply, and the voltage as close as conceivable to the $+9.00 \mathrm{~V}$. Increasingly exact the voltage, higher the exactness. Before the anode in ceaseless utilize unfailingly, there is a need to align it by the standard arrangement, so as to get increasingly exact outcomes. The best condition temperature is around $25{ }^{\circ} \mathrm{C}$, and the $\mathrm{pH}$ esteem is known and dependable, near the deliberate esteem. On the off chance that the acidic example is tested, the $\mathrm{pH}$ estimation of the standard arrangement ought to be 4.00. On the off chance that the soluble example is estimated, the $\mathrm{pH}$ estimation of the standard arrangement ought to be 9.18. Before the $\mathrm{pH}$ cathode estimates distinctive arrangements, wash it with water. Better proposal use deionized water.

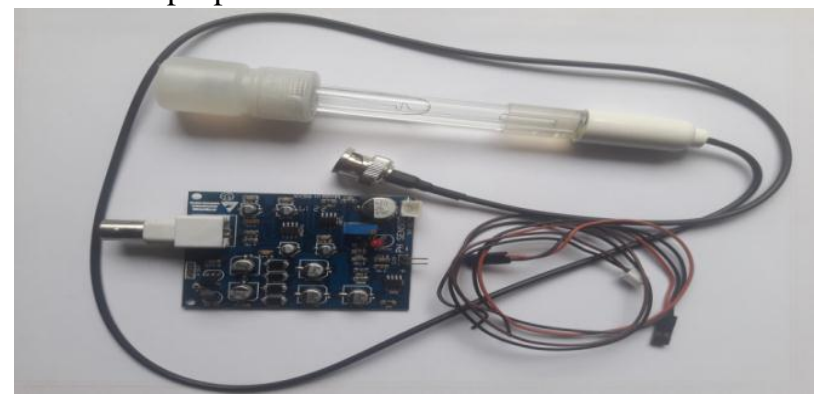

Figure 2 pH sensor module

Table 1 show the specifications of $\mathrm{pH}$ sensor.

\begin{tabular}{|l|l|l|}
\hline S. No & Specifications & Range \\
\hline 1. & Module Power & $5.00 \mathrm{~V}$ \\
\hline 2. & Module Size & $43 \mathrm{~mm} \times 32 \mathrm{~mm}$ \\
\hline 3. & Measuring Range & $014 \mathrm{PH}$ \\
\hline 4. & Measuring Temperature & $060^{\circ} \mathrm{C}$ \\
\hline 5. & Accuracy & $0.1 \mathrm{pH}\left(25^{\circ} \mathrm{C}\right)$ \\
\hline 6. & $\begin{array}{l}\text { Cable Length from } \\
\text { sensor to BNC connector }\end{array}$ & $660 \mathrm{~mm}$ \\
\hline
\end{tabular}

IV. ANALOG TO DIGITAL CONVERTER (MCP3008)

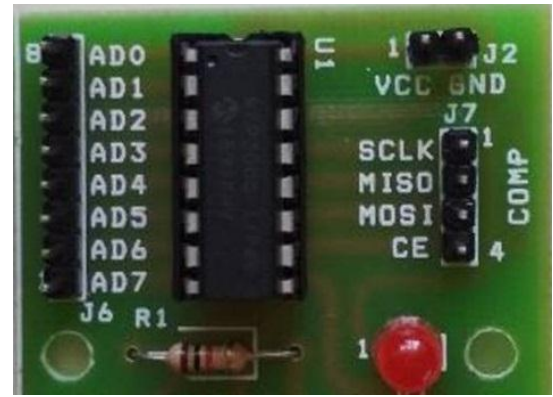

Figure 3 A to D converter (MCP3008)
Figure 3 shows the Analog to Converter module, the MCP3008 is an ease 8-channel 10-bit simple to computerized converter. The exactness of this ADC is like that of an Arduino Uno, and with 8 channels you can peruse many simple signs from the Pi. This chip is an incredible choice on the off chance that you simply need to peruse basic simple signs, as from a temperature or light sensor. On the off chance that you require more exactness or highlights, look at the ADS1x115 arrangement on the following page.

Before you utilize the MCP3008 it will skim this more established Raspberry Pi MCP3008 manage for more data about utilizing it with the Raspberry Pi.

\section{METHODOLOGY ADOPTED}

Figure 4 show the square chart of proposed framework comprises a core of the framework is Raspberry Pi module along with many components like power supply, $\mathrm{pH}$ sensor (SEN0161), Temperature Sensor (LM35), MCP3008 analog to digital converter, DC motor pump and monitor.

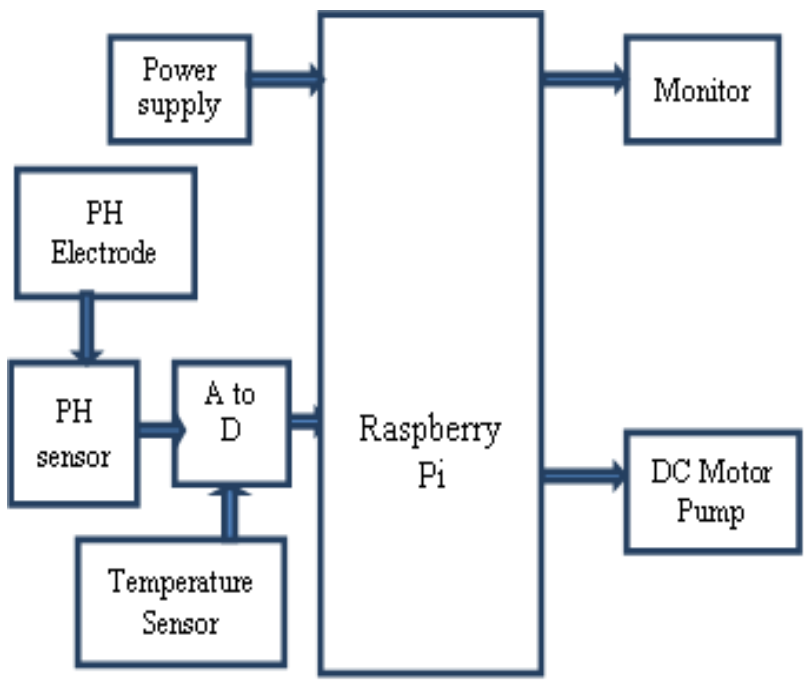

Figure 4 Proposed Block Diagram.

As analog sensors cannot be directly connect to the Raspberry Pi module, analog sensors $\mathrm{pH}$ and temperature is connected to MCP3008 (analog to digital converter) module. Using SPI protocol this MCP3008 module is connected to raspberry module, to transmit analog sensor values. DC motor pump is connected to raspberry Pi module to refresh the water in case of impurity water. 


\section{RESULTS}

The plan and improvement of a framework for continuous observing water quality in Raspberry $\mathrm{Pi}$ is depicted. A contextual analysis is introduced where the stage is produced with a pH sensor (SEN0161) and water Temperature sensor which is utilized to quantify two of the essential parameters of the water. Consequently water is changed utilizing engine siphons Programming should be possible through Python in Raspbian OS.

Water quality information is perused from the sensor and can be sent to be prepared by Raspberry Pi module it transmits the detected information to web as it has inbuilt WIFI module.

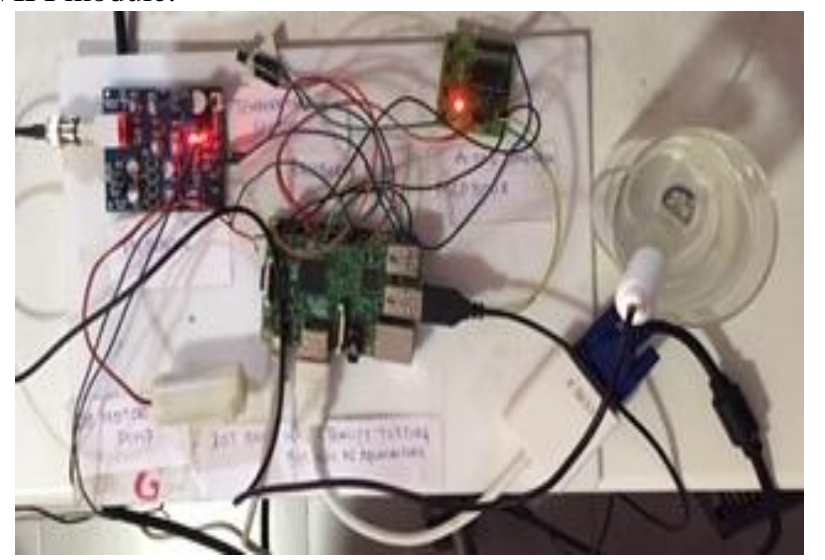

Figure 5 Hardware setup of water quality testing system.

The figure 5 shows the hardware setup of water quality testing system, the analog sensors are connected to $\mathrm{AD} 0, \mathrm{AD} 1$ pins of $\mathrm{MCP} 3008$ module, the MCP3008 pins are connected to Raspberry Pi GPIO pins 8,9,10,11 and DC motor pump is connected to GPIO pin 5 and ground pin.

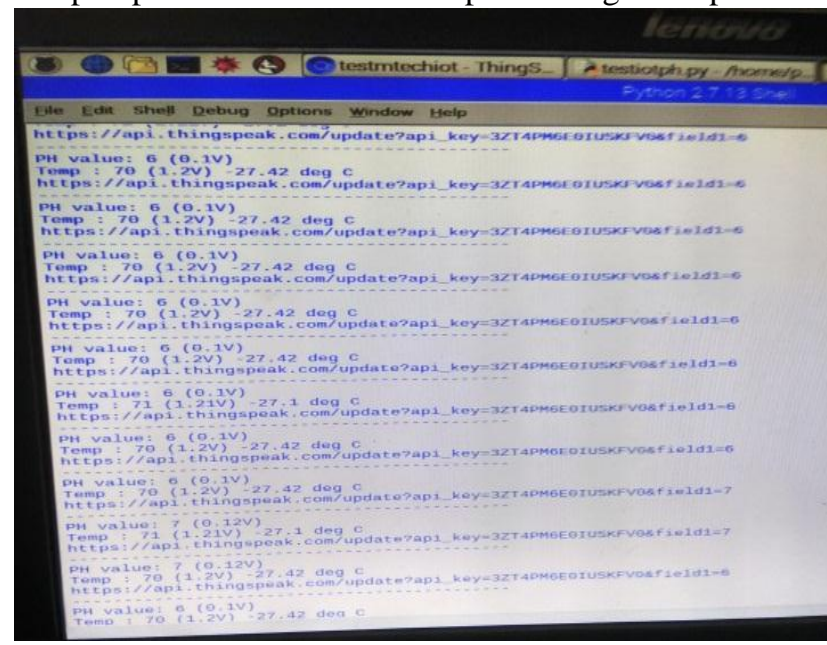

Figure 6 sensor values shown in Python Shell.

The figure 6 shows sensor values in python shell, Python coding is used to develop the water quality testing system in Raspbian OS. Reading temperature and $\mathrm{pH}$ sensor values using GPIO pins shows in the Python shell as well as transmits the values to ThingSpeak website using inbuilt WiFi in Raspberry Pi module. The figure 7 shows the $\mathrm{pH}$ values in ThingSpeak website in graph format, as quality of water reduces the fresh water is filled using the DC motor pump.

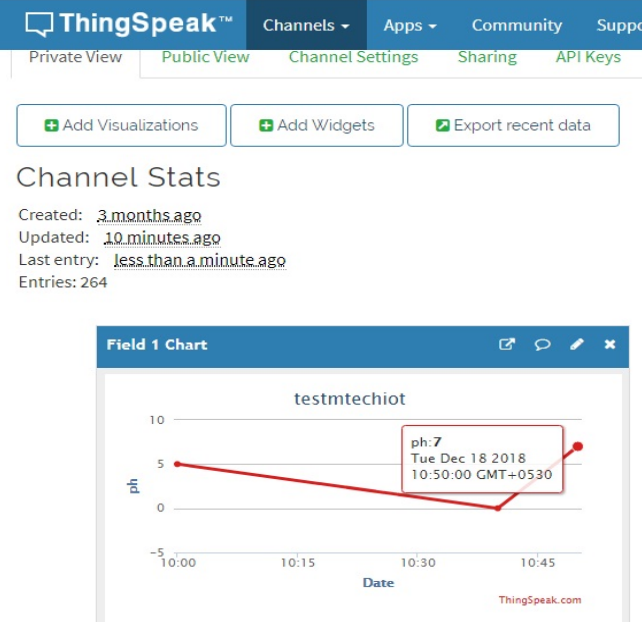

Figure 7 pH values in ThingSpeak website.

\section{CONCLUSION}

The design of IOT based water quality testing system in aquaculture is implemented using Raspberry pi and sensors. This system is used to monitor the sensor values through internet using thingspeak website and the waste water will be removed from the pound and fresh water will be filed in the pound automatically by checking the quality of water..

\section{REFERENCES}

1. Brinda Das, P.C. Jain "Real-Time Water Quality Monitoring System using Internet of Things" 2017 International Conference on Computer, Communications and Electronics (Comptelix) Manipal University Jaipur, alaviya National Institute of Technology Jaipur \& IRISWORLD, July 01-02, 2017.

2. Dr. M. S. Chavan, Mr. Vishal P. Patil "Design and Implementation of IOT Based Real Time Monitoring System for Aquaculture using Raspberry Pi" International Journal on Recent and Innovation Trends in Computing and Communication ISSN: 2321-8169 Volume: 6 Issue: 3 159-161.

3. Liang $\mathrm{Hu}$, Feng Wang, Jin Zhou and $\mathrm{Ku}$ Zhao "A Survey from the Perspective of Evolutionary Process in the Internet of Things", International Journal of Distributed Sensor Networks, Article ID 462752, 2015.

4. Satish Turken, Amruta Kulkarni, "Solar Powered Water Quality Monitoring System using Wireless Sensor Network", IEEE Conf. on Automation, Computing, Communication, Control, and Compressd Sensing, pp281-285, 2013.

\section{AUTHORS PROFILE}

Mr. M. Rohith Ananth Ratnam 1Assistant Professor, ECE Department, Malla Reddy Institute of Technology and Science, Hyderabad, India

Email ID: rohith.ananthratnam@gmail.com

Ms. B. Priyanka M.Tech Scholar, ECE Department, Malla Reddy Institute of Technology and Science, Hyderabad, India

Email ID: priyankabotla7@gmail.com

Mr. J. I. Chakravathy Assistant Professor, ECE Department, Malla Reddy Institute of Technology and Science, Hyderabad, India

Email ID: j.i.chakravarthy@gmail.com

Mr. K. Venkata Phani Raja Assistant Professor, ECE Department, Malla Reddy Institute of Technology and Science, Hyderabad, India

Email ID: venkataphaniraja@gmail.com

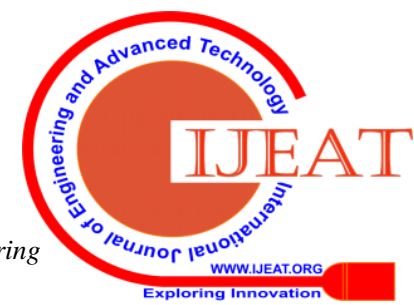

